\title{
Research Paper: Effects of Cortical and Peripheral Electrical Stimulation on Brain Activity in Individu- als with Chronic Low Back Pain
}

\author{
Maryam Sadat Larie ${ }^{1}$, Fateme Esfandiarpour ${ }^{1,2^{*}}$ Q , Forough Riahi $^{3}$ Q , Fateme Derisfard $^{1}$ Q , Mohammad Parnianpour $^{4}$
}

1. Musculoskeletal Rehabilitation Research Center, Ahvaz Jundishapur University of Medical Sciences, Ahvaz, Iran. 2. Department of Family Medicine, Faculty of Medicine and Dentistry, University of Alberta, Edmonton, Canada. 3. Department of Psychiatry, Faculty of Medicine, Ahvaz Jundishapur University of Medical Sciences, Ahvaz, Iran. 4. Department of Mechanical Engineering, Sharif University of Technology, Tehran, Iran.

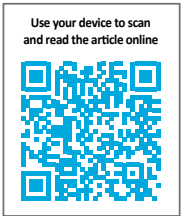

Cftat on Larie M, Esfandiarpour F, Riahi F, Parnianpour M. Effects of Cortical and Peripheral Electrical Stimulation on Brain Activity in Individuals with Chronic Low Back Pain. Physical Treatments. 2019; 9(1):39-46. https://doi.org/10.32598/PTJ.9.1.39

https://doi.org/10.32598/PTJ.9.1.39

\section{$\omega(0)$}

Article info:

Received: 12 Mar 2018

Accepted: 30 Sep 2018

Available Online: 01 Jan 2019

Keywords:

Chronic low back pain, Neuroplasticity, Brain waves, Transcutaneous electrical nerve stimulation, Randomized clinical trial

\begin{abstract}
A B S T R A C T
Purpose: Neuroscience studies suggest that Chronic Low Back Pain (CLBP) is associated with central sensitization, and maladaptive reorganization of the brain; this introduced a new target for LBP treatment. Studies revealed that cortical and peripheral electrical stimulation can be beneficial in regulating brain neuronal activity. However, there is a scarcity of evidence to support the effects of cortical and peripheral stimulation on brain function in patients with CLBP. This double-blind randomized controlled trial investigates the immediate and short-term effects of cortical and peripheral stimulation applied alone and combined on brain activity, pain, and function in patients with CLBP.
\end{abstract}

Methods: Twenty-seven patients with CLBP will be randomozed into three intervention groups using covariate adaptive randomization. The intervention group receives 10 sessions of treatment for 5 days/week as follows: 1: Real Transcranial Direct Current Stimulation (tDCS) and real Transcutaneous Electrical Nerve Stimulation (TENS); group 2: Real tDCS and sham TENS; and group 3: Sham tDCS and real TENS. Brian waves activity, pain intensity, functional ability, and pain threshold will be assessed before, immediately after the first session of treatment, as well as one day and 1 month after the interventions.

Conclusion: The findings of this study provide insight into the effects of cortical and peripheral stimulation applied alone or combined on brain function in patients with CLBP. It also improves our understanding about potential association between CLBP and cortical plasticity.

\footnotetext{
* Corresponding Author:

Fateme Esfandiarpour, $M D$.

Address: Department of Physiotherapy, School of Rehabilitation Sciences, Ahvaz Jundishapur University of Medical Sciences, Ahvaz, Iran.

Phone: +98 (61) 33743101

E-mail:fateme@ualberta.ca
} 


\section{Highlights}

- The effects of cortical and peripheral stimulation on brain activity in patients with LBP are unknown.

- The study will provide high-level evidence about cortical effects of transcranial direct current stimulation and transcutaneous electrical nerve stimulation for low back pain treatment.

- Our finding can assist clinical practice and decision-making process for the treatment of low back pain

\section{Plain Language Summary}

This clinical trial will assess the effects of cortical and peripheral stimulation on brain activity in patients with chronic low back pain. The results of this study may help to find a more effective treatment for chronic low back pain.

\section{Introduction}

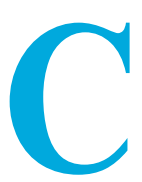

hronic Low Back Pain (CLBP) is the most prevalent chronic pain condition affecting $70-85 \%$ of the adult population [1]. Approximately $10-30 \%$ develop chronic pain, which leads to early retirement and tremendous healthcare costs $[1,2]$. Despite advances in diagnostic tools and techniques, in most cases, it is impossible to identify any specific cause responsible for these symptoms [3, 4]. Moreover, even when anatomical abnormalities are detected, the significance is unclear, making CLBP a challenging condition to treat [5].

In general, the traditional treatment approach to CLBP focuses on peripheral and structural abnormalities assumed to be related to the symptoms. For this aim, a variety of conservative treatments such as medication, acupuncture, exercise therapy, and peripheral electrical stimulation modalities are applied [6-9]. However, a modern neuroscience approach indicates the role of the Central Nervous System (CNS) in the chronicity and persistence of pain in chronic pain conditions such as CLBP $[10,11]$. Mechanisms such as the central sensitization and maladaptive reorganization of a widely distributed neural network involved in pain sensation and perception (i.e. 'pain neuromatrix') contribute to the chronicity of pain [12-16].

Numerous neuroscience studies demonstrated the anatomical and functional reorganization of sensorimotor cortex in patients with CLBP [17-19]. Changes in brain electrical activity were also reported in patients with chronic pain [20]. These findings have introduced a new biological target: cortical changes, for the treatment of LBP.
Transcranial Direct Current Stimulation (tDCS) is a non-invasive tool, widely used in clinical settings for cortical stimulation. Additionally, tDCS is beneficial in regulating brain neuronal activity [21]. Although the precise mechanism is not completely clear, it is assumed that IDCS modulates cortical excitability by altering cell membrane potential [22]. Moreover, Peripheral Electrical Stimulation (PES) using Transcutaneous Electrical Nerve Stimulation (TENS) device may also reduce cortical and spinal excitability. [23-25]. Human and animal studies reported that PES reduces pain by blocking nociceptive afferent impulses (the peripheral mechanism), and activating descending inhibitory pain pathways (the central mechanism) $[25,26]$.

However, the effects of cortical and peripheral electrical stimulation on LBP are controversial. In addition, there is a scarcity of evidence about the effects of cortical and peripheral stimulations on brain activity in patients with CLBP. Limited studies have investigated the effects of cortical stimulation alone, and combined with peripheral electrical stimulation on pain, and brain function in CLBP patients [27-29]. Hazime et al. observed no significant reduction in LBP using $\mathrm{tDCs}$. Other studies suggested that $\mathrm{tDCS}$ applied alone may significantly reduce LBP. However, the results of Hazime et al. support the short-term effectiveness of combined tDCS and TENS in reducing CLBP.

To our knowledge, Schabrun et al. are the only to investigate the immediate cortical changes following combined tDCS and TENS in patients with CLBP. They reported significant improvement in the motor cortical organization of the brain immediately after one session of combined tDCS and TENS. Therefore, there is still insufficient information about the immediate and short-term effects of cortical and peripheral stimulation alone and combined on brain activity changes in patients with CLBP. 
This randomized controlled trial investigated the immediate and short-term effects of cortical and peripheral stimulation, applied alone and combined on the brain activity, pain intensity, pain threshold, and function in patients with CLBP. We hypothesized that combined cortical and peripheral stimulation may provide additional outcomes as well as insight into a more comprehensive approach for CLBP treatment.

\section{Materials and Methods}

In this double-blind (patient and tester) randomized trial, 27 study participants with a diagnosis of non-specific CLPB. They will be allocated to three parallel intervention groups, including: 1: tDCS+TENS; 2: tDCS; and 3: TENS. Non-specific LBP is described as low back pain with an unknown cause [30]. The number of participants was determined based on the results of our pilot study on 5 subjects in each group ( $\beta=0.20$ and $\alpha=0.05$ ) using mean score differences in the overall average beta absolute power of the brain activity after the first session of treatment interventions. Based on this, 7 participants are required in each group. Considering a 20\% attrition, 9 subjects will be included in each group. This study was approved by the Ethics Committee of Ahvaz Jundishapur University of Medical Sciences (IR.AJUMS. REC.1396.713) and was registered in Iranian Registry for Clinical Trials (IRCT20140705018362N3).

\section{Recruitment and eligibility}

We have recruited prospective participants from the rheumatology and orthopedics clinics affiliated to the university through referrals by the physicians and nurses working at the clinics. Then, an investigator contacted the prospective participants to outline the study, ask their interest for participation, and assess general eligibility (age, medical conditions such as depression, neurologic diseases, chronic pain conditions other than CLBP). If interested, an independent physiotherapist will examine the prospective participants in terms of the inclusion and exclusion criteria. The eligible participants will receive detailed information about the study protocol and provided written consent before participation. Thus, approximately 6-9 months are required for collecting and analyzing the data.

The inclusion criteria comprise a history of sustained LBP for more than six months or recurrent LBP with at least three frequencies in the last year needing activity restriction or medical treatment [31]; age range of 30-50 years, and average pain intensity of $>30$ based on a 100 mm Visual Analog Scale (VAS). The study participants will be excluded if they have a systemic metabolic disorder, a history of inflammatory joint disease, neurological disorders, such as a headache, seizure and polyneuropathy, psychological disorders, trauma to low back in the last year, herniated disc with pressure effect on nerve root based on MRI report, spinal surgery, spondylolysis and spondylolisthesis, pregnancy, the use of medications affecting on the brain waves activity, alcoholism and addiction, and past physiotherapy experience [29, 32].

\section{Randomization and allocation concealment}

A covariate adaptive randomization technique will be used to allocate the study participants to the intervention groups [33]. First, an office staff with no other role in the study randomly assign the first 15 study participants into the treatment groups, using sequentially numbered, opaque, and sealed envelopes. Then, Taves thecnique for balance randomization will be used to balance the study participants in the groups based on the covariates of gender and age [33]. The envelopes will be kept in a locked drawer, only accessible to the person in charge of randomization.

\section{Study procedure}

The intervention groups will receive 10 sessions of treatment for 5 days/week. The first group received the real cortical and peripheral stimulation (real tDCS, real TENS), the second group real cortical and sham peripheral stimulation (real tDCS, sham TENS), and the third group received sham cortical and real peripheral stimulation (sham tDCS, real TENS). The cortical stimulation will be performed by tDCS device (Neurostim 2, Medina Teb Company, Tehran, Iran). Two sponge electrodes $(5 \times 7$ $\mathrm{cm}$ soaked in physiologic saline) are placed on the scalp according to the international $10-20$ system $[22,34]$. The anode electrode is placed on the cortical representation of the lumbar paraspinal muscle (C3 or $\mathrm{C} 4: 1 \mathrm{~cm}$ forward and $4 \mathrm{~cm}$ lateral to the vertex point), contralateral to the pain site [35]. The cathode is placed on the supraorbital area contralateral to the anode electrode $[36,37]$.

For the study participants with central lumbar pain, the anode is placed on the contralateral side to the dominant upper limb [38, 39]. The study participants in the real tDCS group will receive 20 min of cortical stimulation with an intensity of $2 \mathrm{~mA}$, density of $0.057 \mathrm{~mA} / \mathrm{cm}^{2}$ [37]. The sham tDCS group will only receive real tDCS for $30 \mathrm{~s}$ and then the intensity will be reduced to zero after $30 \mathrm{~s}[36]$. 
The real TENS group will receive peripheral stimulation using a TENS device (Nu-Tek Med Co., MT2200, China) for 30 minutes with the asymmetric biphasic rectangular waves, a frequency of $100 \mathrm{~Hz}$, and pulse duration of $200 \mu \mathrm{s}$ [40]. Four stimulating electrodes $(6 \times 4 \mathrm{~cm})$ are positioned on both sides of the painful lumbar region in parallel alignment. The intensity is adjusted every 5 min to the sensory threshold. The sham TENS group will receive TENS only for $30 \mathrm{~s}$, and then, the intensity will be reduced to zero.

The overall and regional brain waves activities in both EyesOpened and Eyes-Closed conditions (EO, EC), pain intensity, functional ability, and pain threshold will be assessed before, immediately after the first session of treatment, as well as one day and 1 month after the interventions.

\section{Data collection}

\section{Primary outcome measures}

The primary outcomes are the absolute and relative power of brain waves activity which will be measured using a quantitative Electroencephalography (qEEG, Mitsar-EEG-201, Saint Petersburg, Russia, the sampling frequency: $500 \mathrm{~Hz}$, maximum electrode impedance: 5 $\mathrm{K}$ ohms, and the high pass frequency: $70 \mathrm{~Hz}$ ) machine. The qEEG is a quantitative diagnostic tool for brain waves analysis [41]. Absolute power represents the total energy of each electrode (in microvolt sq) for each frequency band [42]. Relative power is the power of each frequency band relative to the total spectrum [41]. For the qEEG recording, the participant sits on a reclining chair in a semidark quiet room: 19 recording electrodes will be placed on scalp according to the international 1020 system, with the reference electrodes to the earlobes.

The brain waves activity will be recorded in both EO and EC conditions for 5 minutes. In the EO condition, participants will be asked to keep eyes open and look at the fixation mark on the wall. In the EC condition, participants close their eyes, but not sleep. All EEG recordings will be obtained in the morning. The study participants will be instructed to avoid caffeinated drinks in the recording day [43].

The absolute and relative power for frequency bands of delta (1.0-4.0 Hz), theta $(4.0-8.0 \mathrm{~Hz})$, alpha (8.0$12.0 \mathrm{~Hz})$, and beta $(12.0-25.0 \mathrm{~Hz})$ were determined using Neuroguide software. It eliminates the artifacts and analysis the raw file of EEG data. This software uses spectral analysis to create absolute and relative power indices, compared to a normal database (age- and gender-matched healthy controls) $[44,45]$. The database contained 625 people with an age range of 2-82 years (56.8\% were male and $43.2 \%$ were female) with no history of CNS diseases, psychosis, or physical and mental abnormalities [45]. Variance from the normal database is transformed to Z-scores for any point in each banding frequency. Then, for each frequency band, the mean brain activity score of all 19 sites will be calculated as "overall averaging." The mean activity value of each frequency band will also be calculated at frontal $\left(\mathrm{Fp}_{1}, \mathrm{Fp}_{2}\right.$, $\left.\mathrm{F}_{3}, \mathrm{~F}_{4}, \mathrm{~F}_{7}, \mathrm{~F}_{8}, \mathrm{~F}_{\mathrm{z}}\right)$, central $\left(\mathrm{C}_{3}, \mathrm{C}_{4}, \mathrm{C}_{\mathrm{z}}\right)$, parietal $\left(\mathrm{P}_{3}, \mathrm{P}_{4}, \mathrm{P}_{\mathrm{z}}\right)$, occipital $\left(\mathrm{O}_{1}, \mathrm{O}_{2}\right)$ and temporal $\left(\mathrm{T}_{3}, \mathrm{~T}_{4}, \mathrm{~T}_{5}, \mathrm{~T}_{6}\right)$ regions as regional average [41].

\section{Secondary outcome measures}

The secondary outcome measures include pain intensity, functional capacity; and pressure pain thresholds.

Pain intensity will be assessed using a $100 \mathrm{~mm}$ VAS, 0 scores representing no pain and 100 scores very severe pain. The study participants will rate their mean pain intensity of the last 7 days. The validity and reliability of VAS are previously reported [46, 47]. In addition, Kelly et al. indicated the minimum clinically significant difference of $9 \mathrm{~mm}$ for VAS (95\%CI, 6 to13 $\mathrm{mm})$ [48].

Function includes the sit-to-stand, stand-to-sit test, the Timed Up and Go (TUG) test, the modified Schober's test, and the Oswestry Disability Index (ODI) test to assess the study participant's functional ability. In sitto-stand and stand-to-sit test, the participant sits in the middle of a height adjustable chair with no armrest while folding arms across the chest. The participant will be asked to stand up at his/her own pace following the "Go" command by the tester, return to a complete sitting position, and repeat the task for $30 \mathrm{~s}$. The number of repetitions in $30 \mathrm{~s}$ will be recorded as the test's score [49].

Timed Up and Go (TUG) test evaluates balance, and the risk of falling and functional mobility [50-52]. The participant will be instructed to sit back on a standard armchair, stand upon the command "Go" by the examiner, walk to the end of a 3-meters path, turn around and walk back to the chair and sit down, as quickly as possible. The examiner starts timing on the command "Go" time since and stop timing when the participant sits back on the chair. The performance of the participant is based on the time spent to complete the task.

Modified Schober's test evaluates the lumbar pain-free range of flexion by measuring the distance between two reference lines in the erect standing and trunk flexion po- 
sitions [53]. The examiner marks the lumbosacral junction at the level of the posterior superior iliac spine and $15 \mathrm{~cm}$ above. Then, the participant performs full painfree forward flexion. The average of three test trials with a $20 \mathrm{~s}$ time interval will be noted as trunk flexion.

Oswestry Disability Index (ODI) scale is used to score the level of disability for each participant [54]. This questionnaire has 10 sections concerning limitations in daily activities, each containing 6 items with a total score of 5 . Overall, the ODI score ranges between 0-50, expressed as a percentage, with zero scores indicating the ability to perform daily activities without limitation. The disability score of $0-20 \%$ indicates the minimal disability, $21-40 \%$ moderate disability, $41-60 \%$ severe disability, $61-80 \%$ crippling back pain, and $81-100 \%$ score suggests that subject is either bedbound or exaggerating the symptoms [55].

Sensitization pressure algometry (FG-5020, Taiwan, probe size $1 \mathrm{~cm}^{2}$ ) will be used to quantify pressure pain threshold at the lumbar painful site and the thumbnails to assess primary and secondary hyperalgesia (a reflection of central sensitization), respectively [56, 57]. To conduct the tests, the participant lies in a prone position; the pressure is applied perpendicular to the tissue with a slow steady rate [58]. The participant will be instructed to express verbally as soon as feeling pain. The average value of three test trials performed with a $20 \mathrm{~s}$ time interval is recorded as the pressure pain threshold.

\section{Statistical analysis}

A 3 (groups) by 4 (times) mixed Analysis of Variance (ANOVA) will be used to compare intragroup and intergroup differences for each outcome measures. The level of significance was set at $\mathrm{P}<0.05$ and the confidence interval was considered as $95 \% \mathrm{CI}$ for all analysis. The obtained data were analyzed using SPSS.

\section{Discussion}

In this study, we will compare the effects of cortical and peripheral stimulation alone and combined on brain waves activity, along with clinical symptoms in patients with CLBP. In addition, the sham tDCS and sham TENS will be used to control the placebo effects of electrical stimulation. To our knowledge, this clinical trial is the first to evaluate the immediate and short-term effects of cortical and peripheral stimulation on brain activity and clinical signs and symptoms. The obtained results may help physiotherapists in selecting more effective interventions for CLBP treatment. Our findings may provide insight into whether cortical and peripheral stimulation can normalize brain organi- zation, and improve pain and function in patients with LBP. It can also help to determine which treatment strategy may offer additional short-term outcomes.

\section{Ethical Considerations}

\section{Compliance with ethical guidelines}

This study was approved by the Ethics Committee of Ahvaz Jundishapur University of Medical Sciences (IR. AJUMS.REC.1396.713) and was registered in Iranian Registry for Clinical Trial (IRCT20140705018362N3).

\section{Funding}

This study was part of the $\mathrm{PhD}$ desertation of Maryam S. Larie. It was funded by the research project (grant No: PHT-9626), Ahvaz Jundishapur University of Medical Sciences.

\section{Authors' contributions}

Writing of original draft: Maryam Sadat Larie; Review \& editing, funding acquisition, supervision: Fateme Esfandiarpour; Conceptualization, investigation: Maryam Sadat Larie, Fateme Esfandiarpour; Methodology: Maryam Sadat Larie, Forough Riahi, Fateme Derisfard, and Mohamad Parnianpour

\section{Conflict of interests}

The authors declare no conflict of interests related to this manuscript.

\section{References}

[1] Becker A, Held H, Redaelli M, Strauch K, Chenot JF, Leonhardt C, et al. Low back pain in primary care: Costs of care and prediction of future health care utilization. Spine. 2010; 35(18):1714-20. [DOI:10.1097/BRS.0b013e3181cd656f] [PMID]

[2] Johannes CB, Le TK, Zhou X, Johnston JA, Dworkin RH. The prevalence of chronic pain in United States adults: Results of an internet-based survey. Journal of Pain. 2010; 11(11):12309. [DOI:10.1016/j.jpain.2010.07.002] [PMID]

[3] Deyo RA. Diagnostic evaluation of LBP: Reaching a specific diagnosis is often impossible. Archives of Internal Medicine. 2002; 162(13):1444-7. [DOI:10.1001/archinte.162.13.1444] [PMID]

[4] Nachemson A, Vingard E. Assessment of patients with neck and back pain: A best-evidence synthesis. In: Nachemson A, Jonsson E, editors. Neck and Back Pain: The Scientific 
Evidence of Causes, Diagnosis and Treatment. Philadelphia: Lippincott Williams \& Wilkins; 2000.

[5] Fourney DR, Andersson G, Arnold PM, Dettori J, Cahana A, Fehlings MG, et al. Chronic low back pain: A heterogeneous condition with challenges for an evidence-based approach. Spine. 2011; 36:S1-9. [DOI:10.1097/BRS.0b013e31822f0a0d] [PMID]

[6] Lewis A, Morris ME, Walsh C. Are physiotherapy exercises ef fective in reducing chronic low back pain? Physical Therapy Reviews. 2008;13(1):37-44. [DOI:10.1179/174328808X252000]

[7] Ferreira PH, Ferreira ML, Maher CG, Herbert RD, Refshauge K. Specific stabilisation exercise for spinal and pelvic pain: A systematic review. Australian Journal of Physiotherapy. 2006; 52(2):79-88. [DOI:10.1016/S0004-9514(06)70043-5]

[8] Machado LA, Kamper SJ, Herbert RD, Maher CG, McAuley $\mathrm{JH}$. Analgesic effects of treatments for non-specific low back pain: A meta-analysis of placebo-controlled randomized trials. Rheumatology. 2009; 48(5):520-7. [DOI:10.1093/rheumatology/ken470] [PMID]

[9] Van Middelkoop M, Rubinstein SM, Kuijpers T, Verhagen AP, Ostelo R, Koes BW, et al. A systematic review on the effectiveness of physical and rehabilitation interventions for chronic non-specific low back pain. European Spine Journal. 2011; 20(1):19-39. [DOI:10.1007/s00586-010-1518-3] [PMID] [PMCID]

[10] Apkarian AV, Baliki MN, Geha PY. Towards a theory of chronic pain. Progress in Neurobiology. 2009; 87(2):81-97. [DOI:10.1016/j.pneurobio.2008.09.018] [PMID] [PMCID]

[11] Jensen MP. A neuropsychological model of pain: Research and clinical implications. Journal of Pain. 2010; 11(1):2-12. [DOI:10.1016/j.jpain.2009.05.001] [PMID]

[12] Woolf CJ. Central sensitization: Implications for the diagnosis and treatment of pain. Pain. 2011; 152(3):S2-15. [DOI:10.1016/j.pain.2010.09.030] [PMID] [PMCID]

[13] Nijs J, Meeus M, Van Oosterwijck J, Roussel N, De Kooning M, Ickmans K, et al. Treatment of central sensitization in patients with 'unexplained' chronic pain: What options do we have? Expert Opinion on Pharmacotherapy. 2011; 12(7):1087-98. [DOI:10.1517/14656566.2011.547475] [PMID]

[14] Moseley GL, Flor H. Targeting cortical representations in the treatment of chronic pain a review. Neurorehabilitation and Neural Repair. 2012; 26(6):646-52. [DOI:10.1177/1545968311433209] [PMID]

[15] Apkarian AV. The brain in chronic pain: Clinical implications. Pain Management. 2011; 1(6):577-86. [DOI:10.2217/ pmt.11.53] [PMID] [PMCID]

[16] Sterling M, McLean SA, Sullivan MJ, Elliott JM, Buitenhuis J, Kamper SJ. Potential processes involved in the initiation and maintenance of whiplash-associated disorders: Discussion paper 3. Spine. 2011; 36(25 Suppl.):S322-9. [DOI:10.1097/ BRS.0b013e318238853f] [PMID]

[17] Apkarian AV, Sosa Y, Sonty S, Levy RM, Harden RN, Parrish TB, et al. Chronic back pain is associated with decreased prefrontal and thalamic gray matter density. Journal of Neuroscience. 2004; 24(46):10410-5. [DOI:10.1523/JNEUROSCI.2541-04.2004] [PMID]
[18] Flor H, Braun C, Elbert T, Birbaumer N. Extensive reorganization of primary somatosensory cortex in chronic back pain patients. Neuroscience Letters. 1997; 224(1):5-8. [DOI:10.1016/S0304-3940(97)13441-3] [PMID]

[19] Tsao H, Galea MP, Hodges PW. Reorganization of the motor cortex is associated with postural control deficits in recurrent low back pain. Brain. 2008; 131(8):2161-71. [DOI:10.1093/brain/awn154] [PMID]

[20] Burroughs RD. Quantitative EEG analysis of patients with chronic pain: An exploratory study [PhD dissertation]. Texas: University of North Texas; 2015.

[21] Trivedi B. Electrify your mind. New Scientist. 2006; 190(2547):34-7. [DOI:10.1016/S0262-4079(07)60164-X]

[22] Nitsche MA, Cohen LG, Wassermann EM, Priori A, Lang $\mathrm{N}$, Antal A, et al. Transcranial direct current stimulation: State of the art 2008. Brain Stimulation: Basic, Translational, and Clinical Research in Neuromodulation. 2008; 1(3):20623. [DOI:10.1016/j.brs.2008.06.004] [PMID]

[23] Augustinsson LE, Bohlin P, Bundsen P, Carlsson CA, Forssman L, Sjöberg P, et al. Pain relief during delivery by transcutaneous electrical nerve stimulation. Pain. 1977; 4(1):59-65. [DOI:10.1016/0304-3959(77)90087-2]

[24] Burton C. Transcutaneous electrical nerve stimulation to relieve pain. Postgraduate Medicine. 1976; 59(6):105-8. [DOI :10.1080/00325481.1976.11714390] [PMID]

[25] Low J, Reed A. Electrotherapy explained principles and practice [Bakhtiary AH, Persian trans.]. $4^{\text {th }}$ edition. Tehran: Bakhtiary.

[26] Vance CG, Dailey DL, Rakel BA, Sluka KA. Using TENS for pain control: The state of the evidence. Pain Management. 2014; 4(3):197-209. [DOI:10.2217/pmt.14.13] [PMID] [PMCID]

[27] Hazime FA, Baptista AF, de Freitas DG, Monteiro RL, Maretto RL, Hasue RH, et al. Treating low back pain with combined cerebral and peripheral electrical stimulation: A randomized, double-blind, factorial clinical trial. European Journal of Pain. 2017; 21(7):1132-43. [DOI:10.1002/ejp.1037] [PMID]

[28] Mariano T, Burgess F, Bowker M, Kirschner J, van 't WoutFrank M, Halladay C, et al. Transcranial Direct Current Stimulation (tDCS) for affective symptoms of Chronic Low Back Pain (CLBP): A double-blinded, randomized, placebocontrolled trial. Biological Psychiatry. 2018; 83(9):S200-1. [DOI:10.1016/j.biopsych.2018.02.524]

[29] Schabrun SM, Jones E, Elgueta Cancino EL, Hodges PW. Targeting chronic recurrent low back pain from the topdown and the bottom-up: A combined transcranial direct current stimulation and peripheral electrical stimulation intervention. Brain Stimulation. 2014; 7(3):451-9. [DOI:10.1016/j.brs.2014.01.058] [PMID]

[30] Maher C, Underwood M, Buchbinder R. Non-specific low back pain. The Lancet. 2017; 389(10070):736-47. [DOI:10.1016/S0140-6736(16)30970-9]

[31] Gombatto SP, Norton BJ, Sahrmann SA, Strube MJ, van Dillene LR. Factors contributing to lumbar region passive tissue characteristics in people with and people without low back pain. Clinical Biomechanics. 2013. 28(3):255-61. [DOI:10.1016/j.clinbiomech.2013.01.005] [PMID] [PMCID] 
[32] Antal A, Terney D, Kühnl S, Paulus W. Anodal transcranial direct current stimulation of the motor cortex ameliorates chronic pain and reduces short intracortical inhibition. Journal of Pain and Symptom Management. 2010; 39(5):890-903. [DOI:10.1016/j.jpainsymman.2009.09.023] [PMID]

[33] Taves DR. Minimization: A new method of assigning patients to treatment and control groups. Clinical Pharmacology \& Therapeutics. 1974; 15(5):443-53. [DOI:10.1002/ cpt1974155443] [PMID]

[34] Herwig, U, Satrapi P, and Schönfeldt-Lecuona C. Using the international 10-20 EEG system for positioning of transcranial magnetic stimulation. Brain Topography. 2003; 16(2):95-9. [DOI:10.1023/B:BRAT.0000006333.93597.9d] [PMID]

[35] O'Connell NE, Maskill DW, Cossar J, Nowicky AV. Mapping the cortical representation of the lumbar paravertebral muscles. Clinical Neurophysiology. 2007; 118(11):2451-5. [DOI:10.1016/j.clinph.2007.08.006] [PMID]

[36] O'Connell NE, Cossar J, Marston L, Wand BM, Bunce D, De Souza LH, et al. Transcranial direct current stimulation of the motor cortex in the treatment of chronic nonspecific low back pain: a randomized, double-blind exploratory study. The Clinical Journal of Pain. 2013; 29(1):26-34. [DOI:10.1097/ AJP.0b013e318247ec09] [PMID]

[37] O'Connell NE, Wand BM, Marston L, Spencer S, Desouza LH. Non-invasive brain stimulation techniques for chronic pain. Cochrane Database of Systematic Reviews (CDSR). 2010; (9):CD008208. [DOI:10.1002/14651858. CD008208.pub2] [PMID]

[38] Fregni F, Boggio PS, Lima MC, Ferreira MJ, Wagner T, Rigonatti SP, et al. A sham-controlled, phase II trial of transcranial direct current stimulation for the treatment of central pain in traumatic spinal cord injury. Pain. 2006; 122(1-2):197209. [DOI:10.1016/j.pain.2006.02.023] [PMID]

[39] Fregni F, Gimenes R, Valle AC, Ferreira MJ, Rocha RR, Natalle $\mathrm{L}$, et al. A randomized, sham-controlled, proof of principle study of transcranial direct current stimulation for the treatment of pain in fibromyalgia. Arthritis \& Rheumatism. 2006; 54(12):3988-98. [DOI:10.1002/art.22195] [PMID]

[40] Cheing GL, Tsui AY, Lo SK, Hui-Chan CW. Optimal stimulation duration of tens in the management of osteoarthritic knee pain. Journal of Rehabilitation Medicine. 2003; 35(2):628. [DOI:10.1080/16501970306116] [PMID]

[41] Kropotov JD. Quantitative EEG, event-related potentials and neurotherapy. Elsevier, Academic Press; 2009.

[42] Cunha M, Bastos VH, Veiga H, Cagy M, McDowe K, Furtado $\mathrm{V}$, et al. [Changes in cortical power distribution produced by memory consolidation as a function of a typewriting skill (Portuguese)]. Arquivos de Neuro-Psiquiatria. 2004; 62(3A):662-8. [DOI:10.1590/S0004-282X2004000400018] [PMID]

[43] Landolt HP, Rétey JV, Tönz K, Gottselig JM, Khatami R, Buckelmüller I, et al. Caffeine attenuates waking and sleep electroencephalographic markers of sleep homeostasis in humans. Neuropsychopharmacology. 2004; 29(10):1933-9. [DOI:10.1038/sj.npp.1300526] [PMID]

[44] Thatcher R. NeuroGuide Help Manual. Applied Neurosciences, Inc. Florida: 2005.

[45] Thatcher RW, Walker RB, Biver CJ, North DN, Curtin R. Quantitative EEG normative databases: Validation and clin- ical correlation. Journal of Neurotherapy. 2003; 7(3-4):87-121. [DOI:10.1300/J184v07n03_05]

[46] Bijur PE, Silver W, Gallagher EJ. Reliability of the visual analog scale for measurement of acute pain. Academic Emergency Medicine. 2001; 8(12):1153-7. [DOI:10.1111/j.1553-2712.2001.tb01132.x] [PMID]

[47] Carlsson AM. Assessment of chronic pain. I. Aspects of the reliability and validity of the visual analogue scale. Pain. 1983; 16(1):87-101. [DOI:10.1016/0304-3959(83)90088-X] [PMID]

[48] Kelly AM. Does the clinically significant difference in visual analog scale pain scores vary with gender, age, or cause of pain? Academic Emergency Medicine. 1998; 5(11):1086-90. [DOI:10.1111/j.1553-2712.1998.tb02667.x] [PMID]

[49] Judge JO, Schechtman K, Cress E. The relationship between physical performance measures and independence in instrumental activities of daily living. Journal of the American Geriatrics Society. 1996; 44(11):1332-41. [DOI:10.1111/j.1532-5415.1996.tb01404.x] [PMID]

[50] Shumway-Cook A, Brauer S, Woollacott M. Predicting the probability for falls in community-dwelling older adults using the Timed Up \& Go Test. Physical Therapy. 2000; 80(9):896-903. [PMID]

[51] Kristensen MT, Foss NB, Kehlet H. Timed “up \& go" test as a predictor of falls within 6 months after hip fracture surgery. Physical Therapy. 2007; 87(1):24-30. [DOI:10.2522/ ptj.20050271] [PMID]

[52] Valet M, Lejeune T, Van Pesch V, El Sankari S, Stoquart G, Detrembleur C, et al. Assessing the mobility of patients suffering from multiple sclerosis with mild neurological disability: Reliability and responsiveness of the 2-minute walk test and the timed "up-and-go" test. Paper presented at: $21^{\text {st }}$ congress of the ESPRM. 1-6 May 2018; Vilnius, Lithuanian.

[53] Tousignant M, Poulin L, Marchand S, Viau A, Place C. The Modified-Modified Schober Test for range of motion assessment of lumbar flexion in patients with low back pain: A study of criterion validity, intra-and interrater reliability and minimum metrically detectable change. Disability and Rehabilitation. 2005; 27(10):553-9. [DOI:10.1080/09638280400018411] [PMID]

[54] Mousavi SJ, Parnianpour M, Mehdian H, Montazeri A Mobini B. The Oswestry disability index, the Roland-Morris disability questionnaire, and the Quebec back pain disability scale: Translation and validation studies of the Iranian versions. Spine. 2006; 31(14):E454-9. [DOI:10.1097/01. brs.0000222141.61424.f7] [PMID]

[55] Fairbank JC, Pynsent PB. The Oswestry disability index. Spine. 2000; 25(22):2940-53. [DOI:10.1097/00007632200011150-00017] [PMID]

[56] Merskey HE. Classification of chronic pain: Descriptions of chronic pain syndromes and definitions of pain terms. Prepared by the International Association for the study of pain, subcommittee on taxonomy. Pain. 1986; 3(Suppl.):S1-226. [PMID]

[57] Petzke F, Khine A, Williams D, Groner K, Clauw DJ, Gracely RH. Dolorimetry performed at 3 paired tender points highly predicts overall tenderness. The Journal of Rheumatology. 2001; 28(11):2568-9. [PMID] 
[58] Thomson O, Haig L, Mansfield H. The effects of highvelocity low-amplitude thrust manipulation and mobilisation techniques on pressure pain threshold in the lumbar spine. International Journal of Osteopathic Medicine. 2009; 12(2):56-62. [DOI:10.1016/j.ijosm.2008.07.003]

This Page Intentionally Left Blank 